\title{
WORKSHOP PENGEMBANGAN MEDIA PEMBELAJARAN BERBASIS LITERASI DENGAN MEMANFAATKAN LINGKUNGAN ALAM SEKITAR DI SEKOLAH SMPN 2 SEBATIK TENGAH KABUPATEN NUNUKAN
}

\section{Whorshop Media Development of Literacy-Based Learning by Utilizing the Environment in School SMPN 2 Sebatik Tengah in Nunukan District}

\author{
Rita Kumala Sari $^{{ }^{*}}$, Siti Sulistyani Pamuji ${ }^{2}$ \\ 1,2 Jurusan Pendidikan Bahasa Indonesia, Fakultas Keguruan dan Ilmu Penddidikan, \\ Universitas Borneo Tarakan, Jalan Amal Lama, Tarakan \\ * Penulis Korespodensi : thata_ilham@yahoo.co.id
}

\begin{abstract}
ABSTRAK
Pengembangan media pembelajaran merupakan salah satu solusi bagi kurangnya minat siswa dalam belajar serta pemahaman bagi guru dalam inovasi pembelajaran di kelas. Dengan pemanfaatakan lingkungan alam sekitar merupakan cara yang efisien dalam mengembangkan media pembelajaran bagi guru agar dapat di impementasikan dalam kegiatan proses pembelajaran di sekolah. Metode yang akan dicapai dalam pencapaian tujuan pengabdian kepada masyarakat adalah dengan melakukan workshop pengembangan media pembelajaran yaitu dengan membuat produk media pembelajaran berbasis literasi dengan memanfaatkan lingkungan alam sekitar yang meliputi metode tahap pendekatan, metode tahap pelaksanaan dan evaluasi pelaksanaan.Rencana kegiatan berupa workshop pengembangan media berbasis literasi dengan memanfaatkan media lingkungan alam sekitar di SMPN 2 Sebati Tengah Kabupaten Nunukan, sehingga dengan pelaksanaan workshop tersebut dapat menghasilkan beberapa produk media pembelajaran.
\end{abstract}

Kata Kunci : Workshop Pengembangan, Media, Pembelajaran, literasi, lingkungan

\section{ABSTRACT}

Learning media development is one of the solutions to students' lack of interest in learning and understanding of teachers in classroom learning innovations. By utilizing the surrounding natural environment is an efficient way of developing learning media for teachers so that it can be implemented in the learning process activities in schools. The method that will be achieved in achieving the goal of community service is by conducting workshops on the development of learning media, namely by making literacy-based learning media products by utilizing the surrounding natural environment which includes the approach stage method, the implementation and evaluation stage. literacy by utilizing the surrounding natural media at Sebatik Tengah Middle School 2, Nunukan Regency, so that with the implementation of the workshop it can produce several learning media products.

Keywords: Development workshop, media, learning, literacy, Environment

\section{PENDAHULUAN}

Era globalisasi sangat berpengaruh terhadap perkembangan teknologi. Segala bentuk perkembangannya juga berpengaruh terhadap berbagai aspek. Perkembangan pada era globalisasi ini hanya meliputi bidang teknologi, namun perkembangan juga terjadi pada ilmu pengetahuan. Perkembangan ini sangat bermanfaat jika dimanfaatkan dengan sebaik-baiknya.
Tidak hanya memudahkan dalam berbagai aktivitas, namun membuat pekerjaan kita lebih efisien.

Dunia pendidikan mendapat pengaruh besar dari perkembangan ilmu pengetahuan dan teknologi. Sarana dan prasarana pendidikanpun semakin memadai dan lengkap. Hal ini jelas dipengaruhi dengan berkembangnya ilmu pengetahuan dan teknologi. Perkembangan teknologi yang 
begitu pesat cukup dirasakan dari berbagai kalangan baik anak kecil sampai orang dewasa. Dunia pendidikan saat ini sering kali bergantung pada teknologi, karena hal tersebut dapat membantu dalam pembelajaran di sekolah.

Berbagai pembaharuan dalam pendidikan dilakukan agar dapat meningkatkan kualitas dan kuantitas pendidikan. Salah satunya dengan memanfaatkan teknologi sebagai terobosan terbaru dalam meningkatkan kualitas pendidikan yang diperlukan. Untuk meningkatkan proses pembelajaran itu, maka guru dituntut untuk membuat pembelajaran menjadi lebih inovatif sehingga mendorong sisswa dapat belajar secara optimal baik di dalam belajar mandiri maupun di dalam pembelajaran di kelas.

Media pembelajaran dapat digunakan sebagai salah satu pembaharuan agar menarik minat siswa dalam proses kegiatan belajar mengajar. Penggunaan media pembelajaran dalam proses belajar mengajar dapat membangkitkan keinginan dan minat yang baru, membangkitkan motivasi dan rangsangan dalam kegiatan belajar, dan bahkan membawa pengaruhpengaruh psikologi terhadap siswa. Selain membangkitkan motivasi dan minat siswa, media pembelajaran juga dapat membantu siswa meningkatkan pemahaman, menyajikan data dengan menarik, memudahkan penafsiran data, dan memadatkan informasi, serta membantu guru dalam proses kegiatan mengajar.

Pembelajaran Berbasis literasi dengan memanfaatkan Lingkungan Alam sekitar merupakan suatu pembelajaran yang dapat di integrasikan melalui bidang studi pendidikan di sekolah, pendidikan lingkungan hidup dapat dilaksanakan dengan pendekatan interdesipliner, multidisipliner dan transdisipliner di sekolah. Melalui pengembangan media pembelajaran berbasis literasi dengan memanfaatkan lingkungan alam sekitar di sekolah SMPN 2 Sebatik Kabupaten Nunukan dirasa sangat tepat, karena disekolah tersebut sangat dekat dengan lingkungan alam yang masih asri dan belum terjamah.

Berdasarkan hasil wawancara dengan kepala sekolah SMPN 2 Sebatik Tengah oleh Bapak M. Nur Ikhasan, S.Pd mengatakan bahwa dalam proses pembelajaran dikelas guru masih kurang menggunakan media pembelajaran di kelas, terutama dalam proses pebelajaran dikelas yang masih memerlukan pengembangan media pembelajaran yang berbasis literasi dengan memanfaatkan lingkungan alam sekitar di SMPN 2 Sebatik Tengah Kabupaten Nunukan. Sekolah tersebut berada di salah satu kecamatan yang berbatasan langsung dengan Negara Malaysia. Kecamatan Sebatik merupakan salah satu daerah 4P (Perbatasan, Pedalam, Pesisir, Perkotaan) yang memerlukan perhatian lebih dalam hal pendidikan. Daerah Sebatik yang merupakan daerah perbatasan yang berada di garda depan negara Indonesia sangatlah perlu dilakukan upaya peningkatan dan perbaikan kualitas guru-guru dalam proses pembelajaran. Upaya Peningkatan guru-guru dalam proses pembelajaran perlu ditingkatkan dengan pemberian Workshop pengembangan media pembelajaran berbasis literasi dengan memanfaatkan lingkungan alam sekitar di SMPN 2 Sebatik Tengah Kabupaten Nunukan.

Adapun tujuan dalam pengembangan media pembelajaran berbasis literasi dengan memanfaatkan lingkungan alam sekitar di SMPN 2 Sebatik Tengah Kabupaten Nunukan adalah menghasilkan 
produk berupa media pembelajaran, sehingga produk tersebut dapat di implementasikan dalam proses pembelajaran di sekolah tersebut.

Daerah mitra binaan kami memiliki potensi SDA yang banyak, sebagian besar mata pencaharian orang tua siswa sebagai nelayan, petani, dan TKI Negara Malaysia. Hal tersebut menjadi penunjang kehidupan mereka yang seharusnya lebih layak. Melalui kegiatan pelatihan inilah kami mengaharapkan ketercapaiannya kegiatan pengabdian ini untuk sekolah binaan kami. Berikut profil mitra binaan berserta fotofoto pendukung :

a. Nama Sekolah : SMP Negeri 2 Sebatik Barat Alamat Sekolah : JL. Pendidikan RT.03 Balansiku Kecamatan Sebatik Tengah Kabupaten Nunukan

Kepala Sekolah : M. Nurikhsan Ridwan, S.Pd NIP : 197910232008031001

b. Foto-foto Mitra
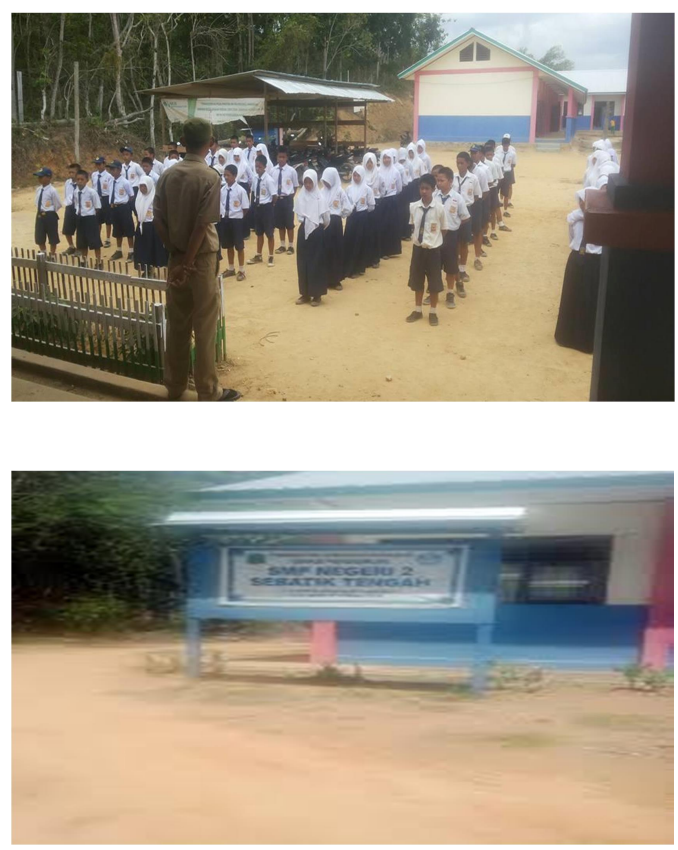

Gambar 1. Foto-foto Lokasi Sekolah Mitra SMPN 2 Sebatik Tengah

\section{Permasalahan Mitra}

Sekolah yang menjadi Mitra dalam kegiatan ini adalah SMPN 2 Sebatik
Tengah (Kabupaten Nunukan). Permasalahan yang dihadapi Setelah melihat uraian analisis situasi di atas, permasalahan yang dihadapi guru-guru di sekolah mitra antara lain sebagai berikut:

1. Guru kurang menguasai media pembelajaran yang berbasis literasi dengan memanfaatkan lingkungan alam sekitar

2. Motivasi belajar siswa yang masih kurang karena siswa lebih senang bekerja membantu orang tua mengelolah kebun dan hasil pertanian

3. Sekolah belum paham menggunakan media pembelajaran yang berbasis literasi dengan memanfaatkan lingkungan alam sekitar.

\section{METODE}

\subsection{Metode Pendekatan}

Metode pendekatan dalam kegiatan ini terbagi menjadi dua cara yaitu penjabaran pemahaman dan pengaplikasian sebagai berikut:

a. Pemberian pengetahuan dan informasi mengenai konsep Media Pembelajaran Berbasis Literasi dengan Memanfaatkan Lingkungan Alam Sekitar

b. Pengaplikasian melalui workshop Pengembangan Media pembelajaran Berbasis Litasi bagi guru-guru hingga menghasilkan draf produk media membelajaran.

Partisipasi mitra dalam pelaksanaan kegiatan ini dimulai dari perencanaan, pelaksanaan kegiatan, analisis permasalahan yang ditemui dalam kegiatan pembelajaran di kelas sampai dengan melakukan wawancara dengan guru di sekolah SMPN 2 Tarakan dan sampai pada tahap akhir menghasilkan produk media pembelajaran. Partisipasi mitra dalam pelaksanaan Program Kemitraan Masyarakat antara lain: 
1) Ikut berpartisipasi dalam perencanaan kegiatan pendampingan antara lain membuat kesepakatan waktu untukjadwal dan penyiapan tempat workshop.

2) Berperan aktif dalam pelaksanaan kegiatan.

3) Menghasilkan produk media pembelajaran berasis literasi.

\subsection{Metode Pelaksanaan Kegiatan}

Kegiatan Berdasarkan permasalahan yang dihadapi sekolah mitra, maka solusi yang ditawarkan adalah perlu adanya workshop Pengembangan Media Pembelajaran Berbasis Litrasi Dengan Memanfaatkan Lingkungan Alam Sekitar di SMPN 2 Sebatik Tengah Kalimantan Utara. Kegiatan pengabdian ini dilaksanakan dengan tahapan sebagai berikut:

\section{a. Pemberian Informasi}

Pemberian informasi kepada guru-guru di sekolah mitra dilakukan dengan cara:

1. Tim Pelaksana datang ke sekolah mitra dengan membuat kesepakatan jadwal dengan kepala sekolah dan guru di sekolah mitra.

2. Tim memberikan informasi tentang perlunya pengunaan media dalam proses pembelajaran dan bagaimana mengembangkan media pembelajaran berbasis literasi dengan memanfatkan lingkungan alam sekitar, sehingga peneliti dapat melaksanakan Workshop pengembangan media bagi guru di SMPN 2 Sebatik Tengah.

\section{b. Workshop Pengembangan Media Pembelajaran Berbasis Literasi}

Workshop yaitu latihan untuk peserta yang bekerja secara perseorangan atau secara kelompok untuk menyelesaikan masalah yang berkaitan dengan pekerjaan/tugas yang sebenarnya dengan maksud untuk memperoleh sebuah pengalaman dan pengetahuan baru. Sehingga dapat dikatakan melalui workshop terjadi sharing informasi dari pemateri kepada para peserta. Hal tersebut merupakan satu interaksi yang terus menerus dalam satu kegiatan hingga terjadinya proses perubahan kreatif yang diprakarsai oleh anggota kelompok atau masyarakat yang sadar diri dan terdidik. Workshop penulisan karya ilmiah di sekolah mitra hendaknya dilihat sebagai penyatuan sumber daya yang ada di dalam yang datang dari luar kelompok masyarakat. Masyarakat memiliki pengetahuan yang berakarkan pada pengalaman dan dalam proses mikro sedangkan pendamping memiliki pengetahuan yang bersifat intelektual formal dan dalam proses makro (Zulkifli, 2010). Kegiatan workshop ini dilakukan dalam dua kali pertemuan yang diuraikan sebagai berikut:

1. Pertemuan pertama

Pada pertemuan ini tim pelaksana sebagai pendamping guru sekolah mitra membantu guru menganalisis permasalahan yang ditemukan dalam kegiatan belajar mengajar di kelas dan menemukan solusi untuk mengatasi permasalahan guru di kelas. Hasil analisis permasalahan akan dituangkan ke dalam latar belakang penulisan karya ilmiah sampai dengan metode penelitian sebagai cara mengatasi permasalahan yang dihadapi guru.

2. Pertemuan ke dua

Pada pertemuan ini merupakan diskusi hasil pelaksanaan tindakan dan data yang diperoleh guru di sekolah mitra. Workshop yang akan dilakukan adalah "Pengembangkan media pembelajaran berbasis literasi dengan memanfaatkan lingkungan alam sekitar" pembahasan 
meliputi cara mengembangkan produk berupa media pembelajaran.

Setelah kegiatan pemberian informasi dan workshop, maka tim pelaksana akan meminta guru untuk memberikan hasil produk berupa media pembelajaran dalam bentuk wujud asli ( cetak) dan softcopy. Untuk selanjutnya melakukan evaluasi terhadap produk pengembangan yang dihasilkan dan pelaksanaan kegiatan workshop.

\section{c. Evaluasi Pelaksanaan Program}

Evaluasi ini dimaksudkan untuk mengetahui tanggapan dari peserta workshop yakni guru dari sekolah mitra tentang pelaksanaan kegiatan pengabdian masyarakat. Evaluasi dilakukan dengan:

1. Lembar evaluasi pelaksanaan pengembangan media pembelajaran berbasis literasi dengan memanfaatkan media alam sekitar di sekolah SMPN 2 Sebatik Barat (Kabupaten Nunukan) dengan skala Likert untuk mengetahui keberhasilan dan peninjauan kembali pelaksanaan kegiatan pengabdian yang meliputi materi pengembangan media pembelajaran yang diberikan pada saat pemberian informasi dan pendamping. Hasil evaluasi kegiatan ini akan digunakan untuk perbaikan kegiatan pengabdian selanjutnya. Hasil yang diperoleh dari instrumen ini akan dianalisis secara deskriptif dan diukur dengan kategorikal, yaitu baik (76-100\%), sedang (56-75\%), kurang (40-55\%) dan buruk (< 40\%) (Arikunto,2010).

2. Evaluasi terhadap pengetahuan guruguru di sekolah pengembangan produk media yang dihasilkan melalui 10 buah pertanyaan yang berkaitan dengan pengembangan media pembelajaran. Hasil yang diperoleh dari instrumen ini akan dianalisis secara deskriptif dan diukur dengan kategorikal, yaitu baik (81-100\%), sedang (61-80\%), kurang (41-60\%) dan buruk (<41\%) (Akbar,2013:81)

3. Evaluasi terhadap produk pengembangan media berbasis literasi harus memenuhi kriteria dan dan Uji Validasi dari para ahli.

\section{HASIL DAN PEMBAHASAN}

Hasil yang telah dicapai dari kegiatan Program Kemitraan Masyarakat ini diperkirakan telah mencapai 100\%. Kegiatan ini dimulai dengan langkah awal adalah membuat analisis kebutuhan dari sekolah SMPN 2 Sebatik Tengah Kabupaten Nunukan. Dari analisis kebutuhan yang didapat adalah sangat minimnya dalam hal prasarana sekolah. Selain itu pemahaman tentang media dan literasi sangat rendah bagi guru di SMPN 2 Sebatik Tengah. Tim PKM memberikan solusi kepada mitra untuk dapat mengadakan pelatihan kepada mitra terutama kepada guru untuk mengikuti pelatihan whorshop Pengembangan Media Pembelajaran Berbasis Literasi dengan memanfaatkan lingkungan Alam sekitar di Sekolah SMPN 2 Sebatik Tengah Kabupaten Nunukan. Pelatihan ini diangap cocok untuk menambah wawasan bagi guru di sekolah tersebut, hal ini ditunjang dengan keadaan kondisi sekolah tersebut yang minim akan prasarana.

Kegiatan Worshop pengembangan dilaksanakan pada tanggal 10 - 12 Agustus 2018. Kegiatan ini berlangsung selama 1 hari ya itu pada tanggal 11 Agustus 2018. Peserta yang mengikuti terdiri dari 30 orang atara lain berasal dari guru SMPN 2, 
SMPN 1, dan SMA 1 Aji kuning Sebatik Tengah. Persiapan yang dilakukan adalah menyiapkan bahan perlengkapan terutama media yang akan dibuat. Media ini berasal dari tumbuhan kering, kertas bekas, karton, spidol, kertas warna, kerdus dan bahanbahan yang tidak digunakan lagi bisa dimanfatkan untuk pembuatan media. Sebelum pelaksanaan kegiatan tim PKM, Narasumber, Mc, dan Mitra melakukan diskusi guna pelaksanaan kegiatan dapat berjalan langsung.

kegiatan pelatihan. Hasil yang didapatkan adalahan para guru dapat membuat media pembelajaran berbasis literasi. Media yang dibuat sangat banyak sekali hal ini dapat terlihat pada gambar dibawah ini.

\section{PENUTUP}

Workshop Pengembangkan media pembelajaran berbasis literasi dengan memanfaatkan lingkungan alam sekitar dimaksudkan untuk memperoleh sebuah pengalaman dan pengetahuan baru mengenai media pembelajaran yang biasa atau belum pernah digunakan oleh guru. Dalam kegiatan workshop tersebut terjadi sharing informasi dari pemateri kepada para peserta. Workshop penulisan karya ilmiah di sekolah mitra hendaknya dilihat sebagai penyatuan sumber daya yang ada di dalam yang datang dari luar kelompok masyarakat.

Kegiatan workshop ini dilakukan dalam dua kali pertemuan pada pertemuan pertama tim pelaksana sebagai pendamping guru sekolah mitra membantu guru menganalisis permasalahan yang ditemukan dalam kegiatan belajar mengajar di kelas dan menemukan solusi untuk mengatasi permasalahan guru di kelas. Pertemuan ke dua merupakan diskusi hasil pelaksanaan tindakan dan data yang
Pada hari Pelaksanaan kegiatan setelah acara dibuka, kegiatan yang dilakukan adalah penyampaian materi pengembangan Media dan Pembelajaran litersi disampaikan terlebih dahulu, oleh Ibu Rita Kumala Sari, M.Pd dan ibu Eva Apriani, M.Pd. Setelah penyampaian materi, tim PKM menjelaskan cara mengembangkan media berbasis literasi dengan memanfaatkan lingkungan alam sekitar.

Pada proses pelaksanaan pembuatan media guru sangat antusias mengikuti, karna disekolah tersebut jarang diadakan diperoleh guru di sekolah mitra. Workshop Pengembangkan media pembelajaran berbasis literasi dengan memanfaatkan lingkungan alam sekitar" membantu guru mengembangkan produk berupa media pembelajaran berbasis alam sekitar. Untuk selanjutnya melakukan evaluasi terhadap produk pengembangan yang dihasilkan dan pelaksanaan kegiatan workshop.

\section{DAFTAR RUJUKAN}

Arsyad, Azhar.2017. Media Pembelajaran. Jakarta: PT Raja Grafindo Persada.

Furchan, Arief. 2011. Pengantar Penelitian Dalam Pendidikan. Yogyakarta: Pustaka Pelajar.

Sadiman, Arief S. 2011. Media Pendidikan Pengertian, Pengembangan, dan Pemanfaatannya. Jakarta: Rajawali Pers.

Sugiono. 2011. Metode Penelitian Kuantitatif Kualitatif dan R \& D. Bandung: Alfabeta Bandung.

$\begin{array}{ccc}\text { Sugiono. 2012. } & \text { Metode } & \text { Penelitian } \\ \text { Kombinasi } & \text { (Mixed } & \text { Methods). } \\ \text { Bandung: } & \text { Alfabeta } & \text { Bandung. }\end{array}$


